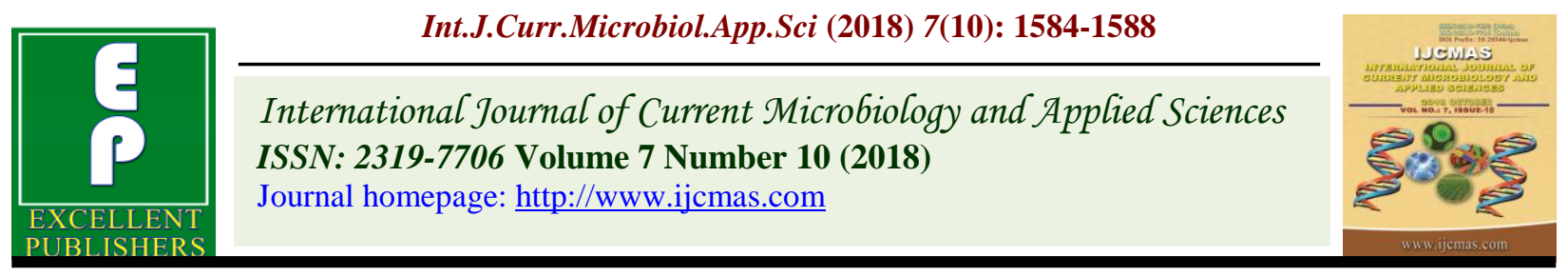

Original Research Article

https://doi.org/10.20546/ijcmas.2018.710.178

\title{
Screening of Sorghum Varieties, Cultivars and Hybrids against Colletotrichum graminicola
}

\author{
K.A. Rewale*, R.W. Deshmukh, S.M. Wahul and R.P. Bhosale \\ Department of Plant Pathology, College of agriculture, Vasantrao Naik Marathwada Krishi \\ Vidyapeeth, Parbhani (MH), India \\ *Corresponding author
}

\section{A B S T R A C T}

\begin{tabular}{|l|}
\hline K e y w o r d s \\
$\begin{array}{l}\text { Colletotrichum } \\
\text { graminicola, Screening, } \\
\text { Incidence, Varieties }\end{array}$ \\
\hline Article Info \\
\hline $\begin{array}{l}\text { Accepted: } \\
\text { 12 September } 2018 \\
\text { Available Online: } \\
10 \text { October } 2018\end{array}$ \\
\hline
\end{tabular}

\section{Introduction}

Sorghum (Sorghum bicolor (L.) Moench), is an important cereal crop in India popularly known as 'Jowar' and large size of among other grain millets is called 'Great millet'. In India the production is concentrated in the four states Maharashtra, Karnataka, Andhra Pradesh and Gujarat; it is next in importance to rice and wheat and is planted on nearly 5.84 million hectares with an annual production of 5.90 million tones (Anonymous, 2013). Maharashtra contributes 23.81 lakh hectares and 8.82 lakh hectares areas with production of 11.19 and 13.25 lakh tonnes in Rabi and Kharif respectively (Anonymous, 2013). Powell et al., (1977) reported that grain yield was reduced by $70 \%$ and more than half the yield loss resulted from incomplete grain fill as verified by $42 \%$ decrease in 1000-seed mass and $17.2 \%$ decrease in seed density. Uttarakhand has been identified as hot spot for the anthracnose disease (Singh and Singh 2008). Anthracnose of sorghum was first reported from Togo in 1902 (Mughogho, 1988).

\section{Materials and Methods}

Fifteen sorghum genotypes obtained from Sorghum Research Station, VNMKV, Parbhani were screened against Colletotrichum graminicola during Kharif, 2014-15 (flowering stage) at Sorghum Research Station, VNMKV, Parbhani under 
natural field conditions. Test cultivars were sown during last week of June with a spacing of $45 \times 15 \mathrm{~cm}$ with three replications. Observations on percent anthracnose disease incidence were recorded 15 days before harvesting of the crop for screening purpose. Based on the percentage anthracnose incidence the cultivars were graded using 0-9 scale (Mayee and Datar, 1986) and grouped into respective categories as follows.

\section{Results and Discussion}

\section{Reactions of sorghum varieties, cultivars and hybrids (Field)}

In order to find out the sources of resistance in sorghum for anthracnose, 15 sorghum varieties, cultivars and hybrids were evaluated during Kharif, 2014-15 at Sorghum Research station, VNMKV, Parbhani. The result (Table
1, PLATE-I and II) indicated that (8.53\%) anthracnose incidence was observed in cv. CSV-8R. E36-1 recorded lowest (2.89\%) anthracnose incidence which was at par with SPV 2250, CSV 27, CSV 20, M 35-1 and significantly superior over rest of the entries.

Categorization of sorghum varieties, cultivars and hybrids

A total of 15sorghum varieties, cultivars, and hybrids were screened during Kharif, 2014-15 against $C$. graminicola under field conditions.

The observations on per cent anthracnose incidence were recorded before harvesting of the crop and test entries of sorghum were graded and categorized as immune, highly resistant, resistant, moderately susceptible, susceptible and highly susceptible.

Table.1 Reaction of sorghum varieties, cultivar and hybrids against $C$. graminicola (field)

\begin{tabular}{|l|l|l|l|}
\hline Sr. No & Entry & Per cent Anthracnose & Varietal Reaction \\
\hline $\mathbf{1}$ & SPH 1724 & 7.28 & $\mathrm{R}$ \\
\hline $\mathbf{2}$ & SPH 1736 & 7.97 & $\mathrm{R}$ \\
\hline $\mathbf{3}$ & SPV 2165 & 6.62 & $\mathrm{R}$ \\
\hline $\mathbf{4}$ & SPV 2242 & 5.99 & $\mathrm{R}$ \\
\hline $\mathbf{5}$ & SPV 2250 & 4.55 & $\mathrm{R}$ \\
\hline $\mathbf{6}$ & CSV-27 & 4.51 & $\mathrm{R}$ \\
\hline $\mathbf{7}$ & CSV-20 & 5.27 & $\mathrm{R}$ \\
\hline $\mathbf{8}$ & CSV-17 & 4.55 & $\mathrm{R}$ \\
\hline $\mathbf{9}$ & M 35-1 & 4.41 & $\mathrm{R}$ \\
\hline $\mathbf{1 0}$ & kekari local & 5.89 & $\mathrm{R}$ \\
\hline $\mathbf{1 1}$ & CSV 23 & 6.03 & $\mathrm{R}$ \\
\hline $\mathbf{1 2}$ & Parbhani Moti & 7.16 & $\mathrm{R}$ \\
\hline $\mathbf{1 3}$ & M35-1 & 4.26 & $\mathrm{R}$ \\
\hline $\mathbf{1 4}$ & E 36-1 & 2.89 & $\mathrm{R}$ \\
\hline $\mathbf{1 5}$ & CSV 8 R & 8.53 & $\mathrm{R}$ \\
\hline & SE \pm & 0.88 & $\mathrm{R}$ \\
\hline & C. D at 5\% & $\mathbf{2 . 5 5}$ & - \\
\hline
\end{tabular}

*Mean of two replications $\mathrm{R}=$ Resistance 
Table.2 Categorization of sorghum varieties, cultivars and hybrids showing various reactions against $C$. graminicola under field conditions during Kharif, 2014-15

\begin{tabular}{|l|l|l|l|}
\hline Disease Scale & Reaction & Per cent infection & Varieties \\
\hline 0 & Immune & No symptom & Nil \\
\hline 1 & Highly resistant & Less than 1 per cent & Nil \\
\hline 3 & Resistant & 1-10per cent & SPH 1724, SPH 1736, SPV 2165, SPV \\
& & 2242, SPV 2250, CSV 27, CSV 17, M \\
& & $\begin{array}{l}\text { 35-1, Kekari local, CSV 23, Parbhani } \\
\text { Moti M35-1, E 36-1 and CSV 8 R }\end{array}$ \\
\hline 5 & Moderately susceptible & 11-25 per cent & Nil \\
\hline 7 & Susceptible & 26-50per cent & Nil \\
\hline 9 & Highly susceptible & 51-100per cent & Nil \\
\hline
\end{tabular}

The percentage anthracnose incidence the cultivers were graded using 0-9 scale

\begin{tabular}{|c|l|l|}
\hline Disease Scale & \multicolumn{1}{|c|}{ Reaction } & \multicolumn{1}{c|}{ Per cent infection } \\
\hline 0 & Immune. & No symptom \\
\hline 1 & Highly resistant & Less than 1 per cent infection \\
\hline 3 & Resistant & 2-10per cent infection \\
\hline 5 & Moderately susceptible & 11-25 per cent infection \\
\hline 7 & Susceptible & 26-50per cent infection \\
\hline 9 & Highly susceptible & 51-100per cent infection \\
\hline
\end{tabular}

Plate.1

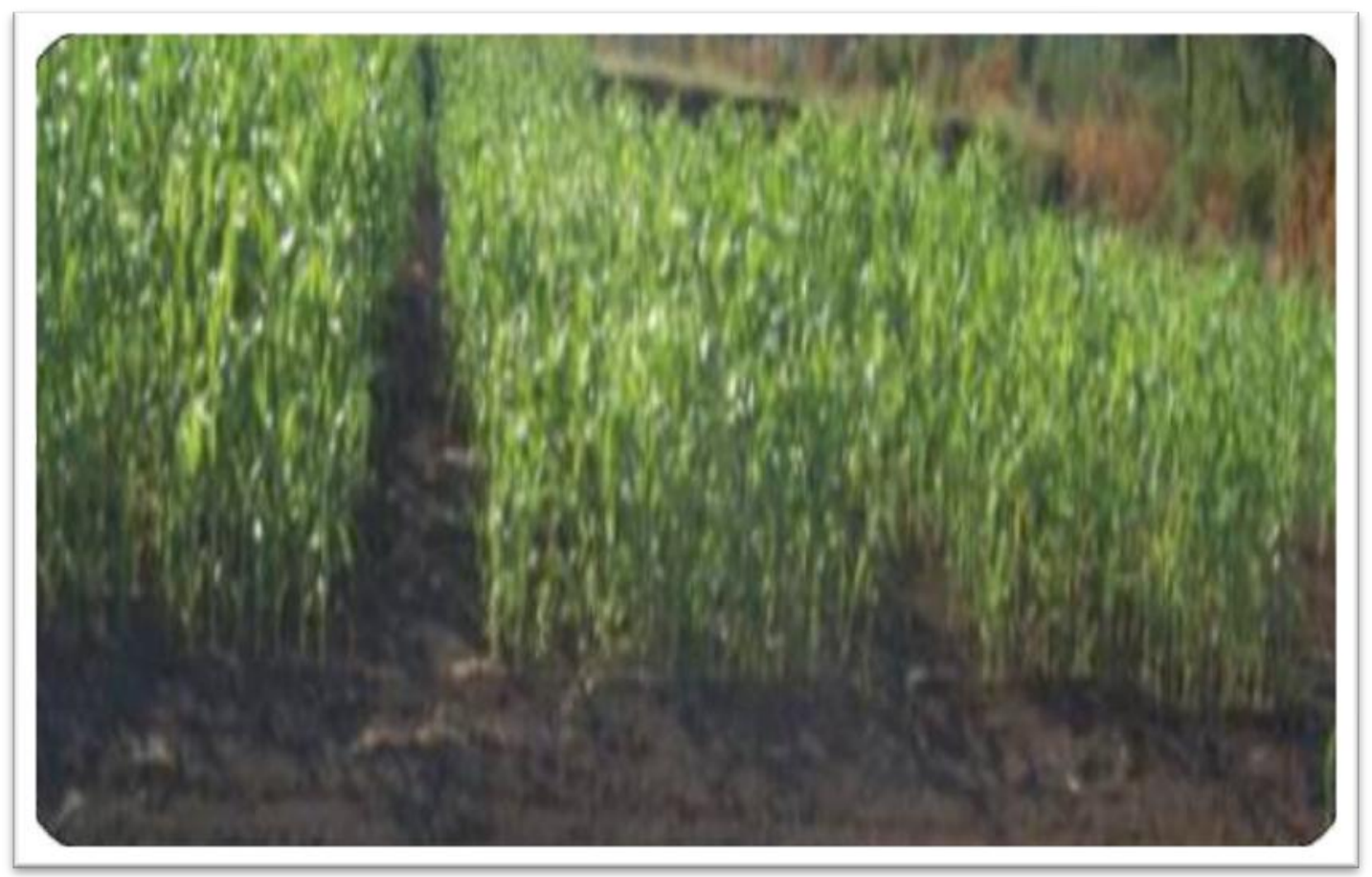




\section{Plate.2}

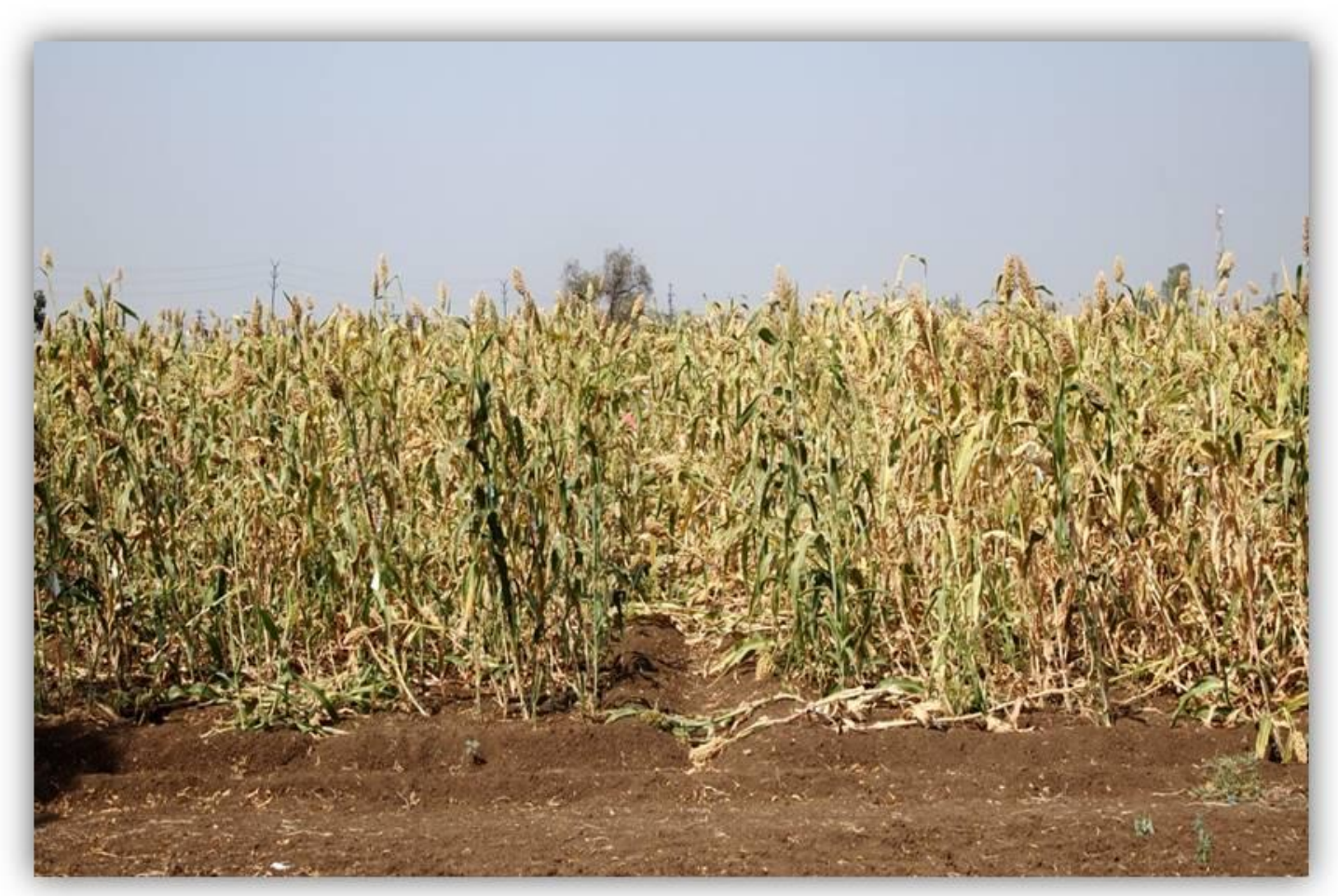

The results (Table 2) indicated that, the cultivars SPH 1724, SPH 1736, SPV 2165, SPV 2242, SPV 2250, CSV 27, CSV 17, M 35-1, Kekari local, CSV 23, Parbhani Moti M35-1, E 36-1 and CSV $8 \mathrm{R}$ were found resistant to anthracnose disease. None of the sorghum entry was found susceptible to anthracnose disease.

Thus, sorghum varieties, cultivars and hybrids found resistant against $C$. graminicola could be further exploited either for breeding disease resistant varieties of sorghum or encouraged for commercial cultivation on large scale.

These results of the sorghum varieties, cultivars and hybrids reactions against $C$. graminicola under natural epiphytotics are on the same line as to that of reported earlier by several workers (Sharma, 1975; Ravindranath, 1978; Sharma et al., 1982; Gupta et al., 1996 and Mishra, 2008).
During this research work under natural epiphytotic conditions, all the fifteen sorghum entries evaluated, exhibited resistance against C. graminicola, with average disease incidence in the range of 2.89 to 8.53 per cent.

\section{References}

Ali, M.E. K. and Warren, H.L. (1992). Anthracnose on Sorghum; Sorghum and Millets Diseases; A Second world Review, 203-208.

Anonymous, (2013). Indian statistical database

Anonymous, (2014). Indian statistical database

Casela, C. R., Santos, F. G. and Ferreira, A. S. (2001). Reaction of sorghum genotypes to the anthracnose fungus Colletotrichum graminicola. Phytopatologia Brasileira, 26(2): 197200. 
Gupta, P. P., Rajesh, Y., Grewal, R. P. S. and Yadav, D. K., (1996). Screening of sorghum germplasm against important foliar diseases. Pl. Dis. Res., 11(1):1-8.

Hiremath, R.V. and Palakshappa, M. G. (1991). Evaluation of high-yielding cultivars and hybrids of sorghum against diseases. Sorghum Newsletter, 32: 39 .

Mishra, M. K. (2008). Screening of sugarcane varities against Red rot caused by $C$. falcatum by diffirent inoculation metho d. J.Mycol.Pl. Pathol, 38(2): 39-399.

Morloy, P. S., Elomo, K. A., Abo, D. A., Onu, I. and Akintayo, I., (2002). Reaction of sorghum genotypes to anthracnose and grey leaf spot diseases in Sudan and Sahel Savanna field conditions of Nigeria. J. of Sustainable Agricul. Research, Ahmadu Bello University, Samaru, P.M.B., 1044, Zaria, Nigeria.

Neya, A. and Normand, M. L. (1998).Responses of sorghum genotypes to leaf anthracnose (Colletotrichum graminicola) under field conditions in Burkina Fago. Crop Protec., 17(1): 47-53.

Rajkule, P. N., Desai, K. B., Rawal, P. P. and Pandya, R. K., (1981). Disease evaluation in advanced sorghum varieties. Sorghum Newsletter, 24: 109.

Ravindranath, V. (1978). Sorghum diseases in India. Proceedings of the International Workshop on Sorghum Diseases ICRISAT, Patencheru, India, 11-15th December, pp.57-66.

Sharma, H. C. (1980). Screening of sorghum for leaf disease resistance in India. In Proceedings of the International Workshop on Sorghum Diseases held on 11-15 December 1978, ICRISAT, Patencheru, India, p.259.

Sharma, H. C. (1975). A practical method of screening sorghum varieties for their resistance to foliar disease of a region. Sorghum Newsletter, 18: 42-43.

\section{How to cite this article:}

Rewale, K.A., R.W. Deshmukh, S.M. Wahul and Bhosale, R.P. 2018. Screening of Sorghum Varieties, Cultivars and Hybrids against Colletotrichum graminicola. Int.J.Curr.Microbiol.App.Sci. 7(10): 1584-1588. doi: https://doi.org/10.20546/ijcmas.2018.710.178 